\title{
Calcium and aluminum-based fillers as flame-retardant additives in silicone matrices. III. Investigations on fire reaction
}

\author{
Siska Hamdani-Devarennes ${ }^{a}$, Claire Longuet ${ }^{a}$, Rodolphe Sonnier ${ }^{\mathrm{a}, *}$, \\ François Ganachaud ${ }^{\mathrm{b}, \mathrm{c}}$, José-Marie Lopez-Cuesta ${ }^{\mathrm{a}}$ \\ ${ }^{a}$ C2MA, Ecole des Mines d'Alès, 6 avenue de Clavières, 30100 Alès, France \\ ${ }^{\mathrm{b}}$ Université de Lyon, F-69003, France \\ ${ }^{\mathrm{c}}$ INSA-Lyon, IMP, UMR5223, F-69621 Villeurbanne, France
}

\section{A B S T R A C T}

The flame retardancy of silicone composites containing calcium- and aluminum-based fillers has been investigated using several methods including cone calorimeter, Pyrolysis Combustion Flow Calorimeter (PCFC), thermogravimetric analysis and pyrolysis-gas chromatography-mass spectrometry analysis (PyGC/MS). The fire reaction of precipitated calcium carbonate, calcite, calcium hydroxide, aluminum trihydrate, boehmite and alumina-based composites was correlated mainly with their thermal stability, while for mica and wollastonite-based composites, a barrier effect was also evidenced. The endothermic effect was not established as an efficient flame retardancy mechanism for the silicone composites containing hydrated fillers. Mica composite exhibited the best flame retardancy, in terms of depressed HRR, among all investigated formulations. Finally, a unique behavior was observed during the cone calorimeter test of calcium hydroxide-based composite, which co-crystallization with silica occurs exclusively at high heat flux.

Keywords:

Silicone

Flame retardancy

Mineral filler

Cone calorimeter

\section{Introduction}

While most of organic polymers are acceptable for their general insulation properties, in areas of fire, these materials may not provide a high temperature resistance during a long period of time. In addition, they generally lead to a spread of flames, an emission of smoke and a release of combustion products that are dangerous to humans and injurious to equipment and human health. That is why nowadays, strong emphasis is given on non-halogenated flame retardants and nano-scaled additives to enhance the fire stability of polymers [1]. Besides these, the use of polymers with high thermal stability and fire resistant behavior has been developed as a new, future approach to flame retardant materials [2].

Due to their unique properties against fire, PDMS (polydimethylsiloxane) is widely used for applications at high temperature such as in electrical wire and cable [3-7]. To fulfill continuously harsher specifications, researchers have long addressed studies to improve the flame retardant properties of silicones, including addition of fillers, polymer structure modification by incorporation

\footnotetext{
* Corresponding author. Tel.: +33466785659.

E-mail address: rodolphe.sonnier@mines-ales.fr (R. Sonnier).
}

of flame retardant heteroatoms into siloxane backbone, or formulation issues (for a very recent review on this topic, see Ref. [8]). The flame retardant mechanism in silicone composites in the presence of mineral filler(s) is believed to take place in the condensed phase because of the formation of a barrier layer from silica ash reinforced by mineral fillers [9]. In the presence of platinum (Pt), another mechanism implies the formation of a highly crosslinked polymer through the radical activation/cross-coupling of silicone chains [1012]. While burning, silicones also show a slow decomposition rate without flaming drips, minimal sensitivity to external heat flux and low or almost zero emissions of toxic smoke [13]. Even if some mineral fillers have been already used to impart the flame retardancy of PDMS (for example, kaolin, magnesium hydroxide [14], mica [15], calcium carbonate [16]), no studies, to our knowledge, have proposed a systematic comparison of fire behavior of numerous, differently filled composites.

The cone calorimeter technique is at present the most advanced method for assessing materials' reaction to fire on a small scale. The cone calorimeter brings quantitative analysis to materials flammability research by investigating parameters such as heat release rate (HRR), time to ignition (TTI), total heat release (THR), mass loss rate (MLR), and their derivatives [17]. Heat release rate is the key measurement required to assess the fire hazard of materials and 
products as it quantifies the fire size, the rate of fire growth and consequently the release of associated smoke and toxic gases [18]. Peak of heat release rate is considered the single most important variable in characterizing the 'flammability' of organic materials and their consequent fire hazard [19]. The shape of the HRR curves is known to depend strongly on the mode of degradation of the material [20]: a continuous increase in heat release rate up to high levels shows that the material is not well flame retarded; on the opposite, a low pHRR followed by a pseudo-plateau or a slow decrease in HRR indicate a controlled degradation of the condensed phase. Such behavior is due to a slowdown of the pyrolysis rate, via e.g. a barrier effect that insulates the polymer and limits the heat and gases transfer between the flame and the condensed phase. Under a heat flux of $50 \mathrm{~kW} / \mathrm{m}^{2}$, the HRR for most silicones falls within the range of $60-150 \mathrm{~kW} / \mathrm{m}^{2}$ [13]. Beside the cone calorimeter test, Pyrolysis Combustion Flow Calorimeter (PCFC) has been developed these last few years as a viable method for determining combustion parameters of materials at a micro-scale [21]. Since several physical effects (but not all) are not efficient at this scale, the complementary association of cone calorimeter and PCFC should become in the future an attractive method to discriminate the main modes of action of a flame retardant [22].

The calorimetric studies presented here aim at closing our series of investigations on the thermal and fire behavior of silicone composites filled with calcium and aluminum-based fillers. In our previous papers, we reported the thermal behavior and the residue cohesion of silicone composites containing aluminum and calciumbased fillers $[23,24]$. The modes of action of mineral fillers could be four-fold: i) an increase in the thermal stability of the silicone matrix, and/or ii) a change in the degradation pathway leading to a slowdown of the degradation with or without charring, and/or iii) an insulating effect due to the formation of a barrier layer, and/or finally iv) a slowdown of the pyrolysis rate due to an endothermic effect. On the contrary, flame poisoning, generally associated with halogenated compounds, is not expected to be an effective modeof-action in our mineral filled formulations. As a reminder, some of the tested fillers are non-combustible gas-emitting materials: hydrated fillers, such as aluminum hydroxide, boehmite, and calcium hydroxide, split off water, whereas carbonate fillers, e.g. calcite and precipitated calcium carbonate (PCC), release carbon dioxide. These types of fillers have been known to improve the flame retardancy of polymers by physical action through gas dilution or cooling due to their endothermic decomposition [20].

It is the objective of this article to determine the modes of action of the various mineral fillers under study for various fire scenarios. This work is divided in three parts: the first part focuses on cone calorimeter results and residues' analyses, the second part describes Pyrolysis Combustion Flow Calorimeter (PCFC) tests, as well as a quantitative analysis of related volatiles products by PyGC/MS; a third part proposes a concise discussion on the factors that we believe, influence the fire reaction of silicone composites.

\section{Materials and methods}

\subsection{Materials}

The silicone matrix was kindly supplied by Bluestar Silicones (Saint Fons, France). It contains $74.4 \mathrm{wt} . \%$ of vinyl-terminated polydimethylsiloxane (Mw of 550,000 g/mol), $25 \mathrm{wt} . \%$ of $\mathrm{D}_{4}$-modified silica and 0.6 wt.\% of 2,5-dimethyl-2,5-di(tert-butyl peroxy)hexane as a crosslinking agent. PCC, wollastonite, and boehmite were given by Solvay, Nyco minerals and Nabaltec respectively. ATH was purchased from Martinswerk, alumina from Nabaltec and mica from Kaolin International. For further characteristics of the fillers, please report on the previous papers of this series [23,24] (see also Table S1 in Supporting Information).

\subsection{Sample preparation}

Composite formulations consisting of 20 wt.\% of silica and 20 wt.\% of filler were prepared using a HAAKE internal mixer at a temperature of $45{ }^{\circ} \mathrm{C}$, shear rate of $60 \mathrm{rpm}$ and mixing time of $60 \mathrm{~min}$. The HAAKE internal mixer has two rotors running in a contra-rotating way to blend the filler and matrix. Thereafter, filled silicone was cross-linked under heat pressure of 90 bars at $150{ }^{\circ} \mathrm{C}$ during 15 min to obtain a sheet of elastomer with dimensions of $100 \mathrm{~mm} \times 100 \mathrm{~mm} \times 4 \mathrm{~mm}$.

\subsection{Methods}

A cone calorimeter from Fire Testing Technology (FTT-UK) was used to characterize the forced flaming behavior according to ISO 5660. Sheet specimens were burnt horizontally in air using different incident heat fluxes of 35,50 , and $75 \mathrm{~kW} / \mathrm{m}^{2}$ in the presence of an igniter's spark. Two typical curves were plotted from these experiments: the heat release rate (HRR) as a function of time, and the residue versus time (see the typical curves obtained for the matrix without FR filler, Fig. 1 for a heat flux of $50 \mathrm{~kW} / \mathrm{m}^{2}$ ). From both curves, different parameters were quantified, such as time to ignition (TTI), peak of heat release rate (PHRR) and total heat release (THR) (Fig. 1). THR was taken over the first 500 s, i.e. after flame out. All measurements were repeated (between 3 and 5 samples) and the results were averaged.
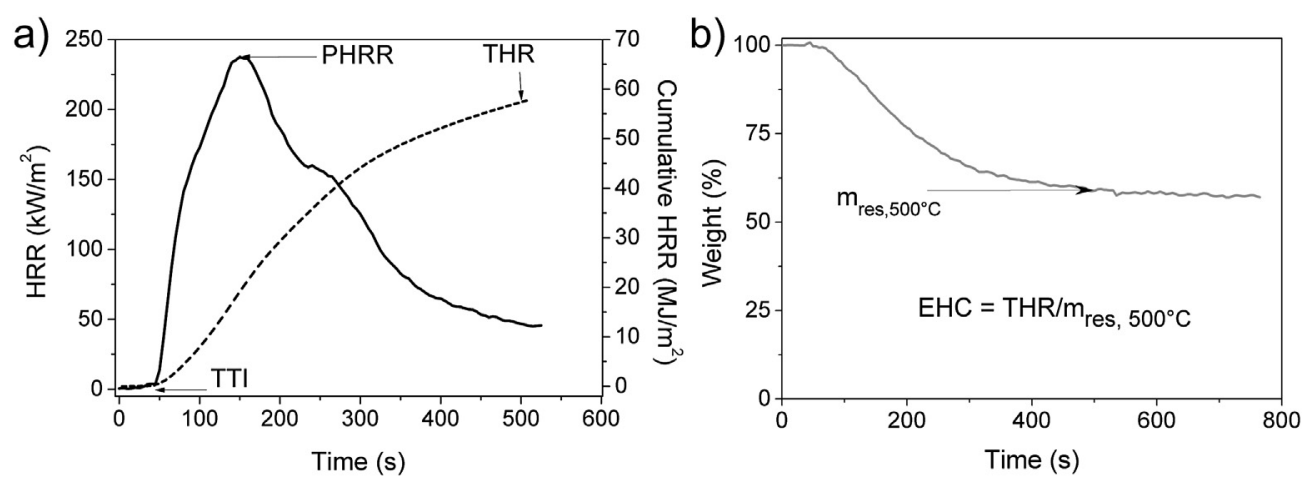

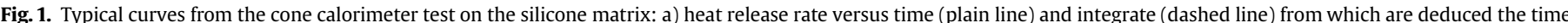

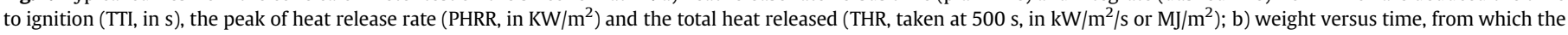
effective heat of combustion (EHC, in $\mathrm{kJ} / \mathrm{g}$ ) is used for further calculations (see text for details). 


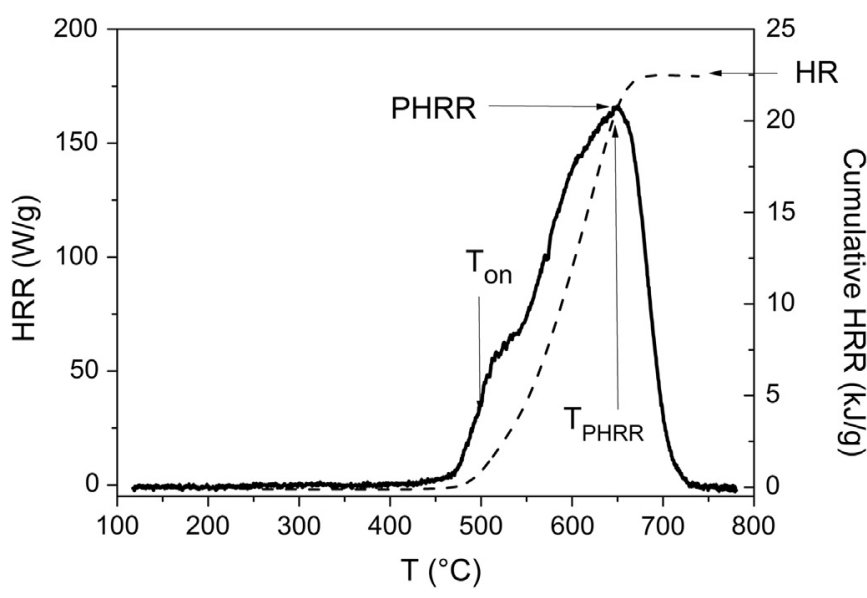

Fig. 2. Typical curves from PCFC test on the silicone matrix: heat release rate versus temperature (plain line) and integrate (dashed line) from which are deduced the onset temperature $\left(T_{\text {on }}\right.$, taken at HRR of $30 \mathrm{~W} / \mathrm{g}$, in $\left.{ }^{\circ} \mathrm{C}\right)$, the peak of heat release rate (PHRR, in $\mathrm{W} / \mathrm{g})$, temperature at PHRR $\left(T_{\mathrm{PHRR}}\right.$, in $\left.{ }^{\circ} \mathrm{C}\right)$ and the heat released $(\mathrm{HR}$, taken at full degradation, in $\mathrm{kJ} / \mathrm{g}$ ).

Pyrolysis Combustion Flow Calorimeter (PCFC) apparatus, also from FTT-UK, was used to pyrolyze $3 \pm 1 \mathrm{mg}$ of sample by heating up to $780{ }^{\circ} \mathrm{C}$ at a heating rate of $1{ }^{\circ} \mathrm{C} / \mathrm{s}$ under a nitrogen flow. The gases produced during pyrolysis were sent into a combustor and burnt at a temperature of $900{ }^{\circ} \mathrm{C}$ in the presence of oxygen (20\%). The energy released by the oxidation of the volatile pyrolysis products at high temperature has no effect on the pyrolysis. PHRR and heat release (HR) of samples were determined and each measurement was performed at least five times (up to ten times) (see an example for the silicone matrix alone in Fig. 2). The results were averaged with an error of less than $5 \%$, while the error on the measurement of the temperature of PHRR ( $\left.T_{\text {PHRR }}\right)$ was typically less than $1 \%$.

The thermal decomposition was investigated by thermogravimetry (TG) using a TGA Pyris Manager 6. All measurements were performed at least three times for $10 \pm 0.5 \mathrm{mg}$ sample under nitrogen with a heating rate of $10{ }^{\circ} \mathrm{C} / \mathrm{min}$ (see the first part of this series for details [23]). The standard deviation for the TG results was on average $\pm 0.5 \mathrm{wt} \%$.

The surface morphology of residues from cone calorimeter tests was observed on a Hitachi S-4300 environmental scanning electron microscope (ESEM) using an acceleration voltage of $15 \mathrm{kV}$. Crystallinity of finely ground residue was investigated on a Bruker X-ray diffractometer (XRD) using $\mathrm{Cu} \mathrm{K} \alpha$ radiation.

Py-GC/MS analyses at temperature of PHRR were carried out on a Pyroprobe 5000 pyrolyser (CDS Analytical) interfaced to a 450-GC gas chromatograph (Varian) by means of a chamber heated at $270{ }^{\circ} \mathrm{C}$. The column is a Varian Vf-5 ms capillary column
(30 $\mathrm{m} \times 0.25 \mathrm{~mm}, 0.25 \mu \mathrm{m}$ ) and helium $(1 \mathrm{~mL} / \mathrm{min}$ ) was used as the carrier gas. Less than one mg samples were first placed in a quartz tube between two pieces of quartz wool, and successively flash pyrolyzed for $5 \mathrm{~s}$ under helium at PHRR temperature measured using PCFC test for each composite. Then the gases were sent to the gas chromatograph for $5 \mathrm{~min}$ and from the GC transfer line to the ion trap analyzer of the 240-MS mass spectrometer (Varian) through the direct-coupled capillary column. The released volatiles detected by GC/MS have molar masses mandatory larger than $60 \mathrm{~g} /$ mol. The data for the matrix alone are given in supporting information (Fig. S1).

\section{Results and discussion}

\subsection{Cone calorimeter tests and residue analyses}

\subsubsection{Burning process during cone calorimeter test}

The burning process during cone calorimeter test was visually observed for all silicone composites under various heat fluxes. Fig. 3 presents the burning behavior from the stage where the fire was already on. In all cases, similar steps were observed: before ignition, few opaque smokes develop and after passing TTI, fire starts until it spreads over the whole surface without drips. All composite residues showed the same bumpy, white solid platelets on the surface, whereas on their interior a thick cemented layer was observed, as in Fig. 3d. More precisely, for the same heat flux, the solid platelets formed after burning of ATH, alumina and boehmite composites were always smaller than the ones observed for composites containing mica and calcium-based fillers (see Fig. S2 for matrix alone and all composite residues). Unlike other composites, those filled with mica or wollastonite always presented scratches on surface through the formation of thin layers before the platelets formation (Fig. S3). For calcium hydroxide-filled formulations, a cohesive outer layer was observed under the lowest heat flux, whereas at $50 \mathrm{~kW} / \mathrm{m}^{2}$ the surface layer was clearly damaged (Fig. S4).

\subsubsection{Typical heat release/time curves}

During combustion in the cone calorimeter test, the heat released by sample combustion at different heat fluxes was recorded. HRR curves for calcium and aluminum-based filled composites are presented in Fig. 4. Three irradiances were tested, namely 35, 50 and $75 \mathrm{~kW} / \mathrm{m}^{2}$. At low heat flux, all composites show an HRR pseudo-plateau, whereas at the highest heat flux, great differences could be noticed. The mica composite exhibits a very smooth HRR curve, which plateaus at relatively low time (200 s) without too large weight losses (around 10-20 wt.\%, see Fig. S5). On the contrary, the other aluminum-based filler composites exhibit high pHRR attained at a relatively high mass loss (Fig. S5). Calciumbased filler composites show intermediate behaviors. Some HRR curves (mainly for ATH and calcium hydroxide at $50 \mathrm{~kW} / \mathrm{m}^{2}$ )
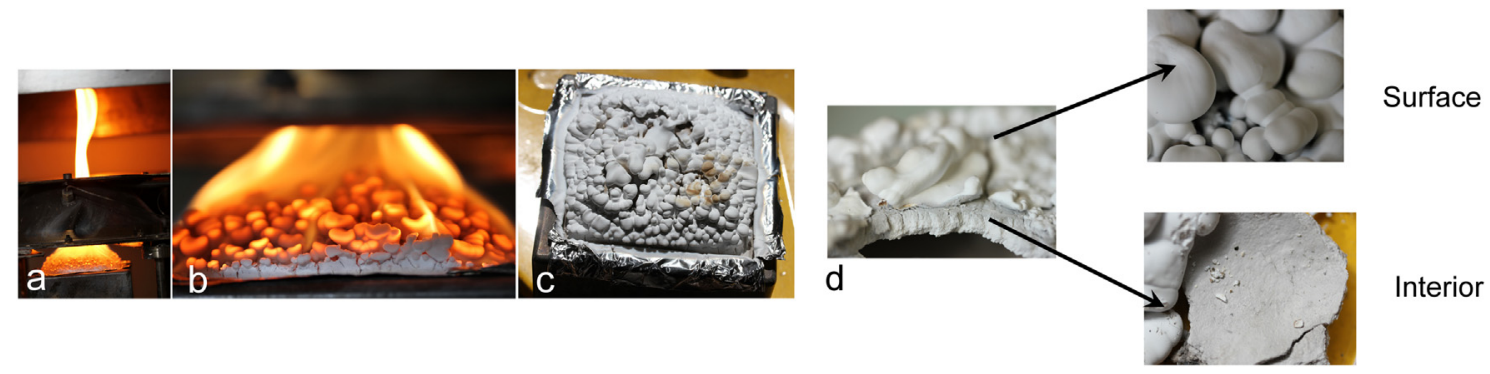

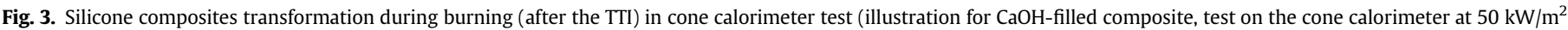
irradiance): (a) fire spread, (b) white solid platelet formation, and (c) appearance of the final residue; (d) structure at the surface and inside the residues. 

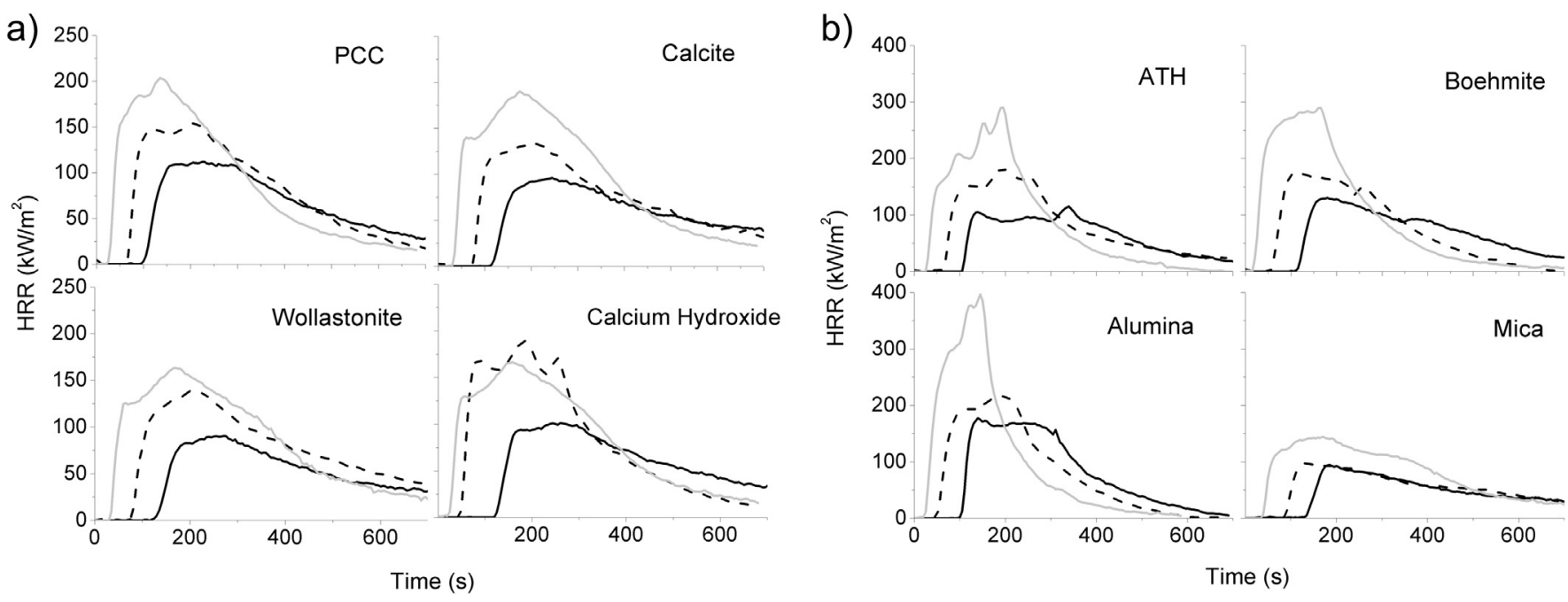

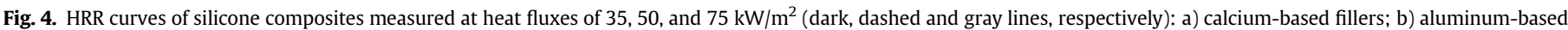
fillers.

exhibit several peaks; these two fillers have been shown previously to release non-combustible gases (water) at relatively low temperature (from $200{ }^{\circ} \mathrm{C}$ for ATH, and between 400 and $450{ }^{\circ} \mathrm{C}$ for calcium hydroxide [23]). Boehmite also releases water, but above $450{ }^{\circ} \mathrm{C}$. Water release may induce cracks on the surface, inhibiting the insulating effect of the silica ash and mineral particles. This effect would not be observed at $75 \mathrm{~kW} / \mathrm{m}^{2}$ for calcium hydroxide composite because of a ceramization process (see below).

\subsubsection{HRR curves' exploitation}

The fire behavior of silicone composites in terms of PHRR, TTI and THR during the cone calorimeter test was then measured. All these data are reported in Fig. 5 for the different heat fluxes. When the heat flux increases, TTI decreases sharply and pHRR increases for all composites [25]. TTI is the highest for mica composite at all heat fluxes among other aluminum-based filler composites. The calcium-based filler composites exhibit an intermediate TTI, with calcium hydroxide composite having the lowest TTI at high irradiance. These tendencies are alike for pHRR: the mica composite exhibits the lowest pHRR, while other aluminum-based filler composites display the highest ones, particularly at high heat flux, even higher than the matrix alone filled with $25 \mathrm{wt} \%$ of silica (see Fig. 1). The differences between calcium and aluminum-filled elastomers are confirmed by the shape of HRR curves (Fig. 4). Particularly, ATH and alumina composites exhibit HRR curves without HRR plateau and a pHRR at high mass loss which is indicative of a poor flame retardancy. Finally, calcium hydroxide based composite shows again a peculiar behavior, with a lower pHRR at $75 \mathrm{~kW} / \mathrm{m}^{2}$ than at $50 \mathrm{~kW} / \mathrm{m}^{2}$ (this point will be discussed later). For all formulations, THR increased with increasing heat flux. This means that the temperature in the condensed phase is too low to degrade all combustibles into volatiles (according to Schartel and Hull, maximum temperatures of 520,610 and $700{ }^{\circ} \mathrm{C}$ are attained for heat fluxes of 35,50 and $75 \mathrm{~kW} / \mathrm{m}^{2}$, respectively [17]).

\subsubsection{Weight losses and extensions}

The measured residual weight of silicone composites during burning in cone calorimeter was systematically tracked (Fig. 6 and Fig. S5). All mass loss rates during combustion were coherent with heat release evolution, i.e. a plateau seen on HRR curve was related to a low degradation rate of composites. Note that the final residues were systematically larger than those obtained after pyrolysis at
$900{ }^{\circ} \mathrm{C}$, as measured by TGA (dashed limits in Fig. 6 and S5, to be compared to thermograms in Fig. S6). Particularly, Fig. 6 shows the singularity of mass loss curves for wollastonite and calcium hydroxide composites. Mass loss at $75 \mathrm{~kW} / \mathrm{m}^{2}$ slows down and becomes lower than at $50 \mathrm{~kW} / \mathrm{m}^{2}$ after 450 and $100 \mathrm{~s}$, respectively. This point is in agreement with HRR curves: for wollastonite composite, at $75 \mathrm{~kW} / \mathrm{m}^{2}$, HRR decreases faster to end up below the value found at $50 \mathrm{~kW} / \mathrm{m}^{2}$. This is probably due to the formation of microbridges between silica and wollastonite particles at high temperature, observed in our previous work [24], and perhaps limiting the composite decomposition via slow pyrolysis. This effect is even stronger for calcium hydroxide, for which the HRR curve at $75 \mathrm{~kW} / \mathrm{m}^{2}$ is systematically lower than at $50 \mathrm{~kW} / \mathrm{m}^{2}$. Such behavior would be ascribed to the formation of crystals of wollastonite from reaction of calcium oxide with silica at high temperature, crystals which act as barrier layer and slow down the pyrolysis rate in the condensed phase (see below).

Hshieh [9] has shown that the effective heat of combustion (EHC, defined as the ratio between the THR and the mass loss) should not be calculated for silicones, since amorphous silica-ash deposition on the surface of the samples distort the results. He proposed instead to consider a fixed heat of combustion for PDMS (i.e. $24.6 \mathrm{~kJ} / \mathrm{g}$ for complete combustion) ${ }^{1}$ and to calculate the consumed polymer fraction as the ratio between THR and this constant value of heat of combustion (see also the work of Genovese and Shanks [14]). The calculated fraction of consumed PDMS is reported in Fig. 5d for all composites and heat fluxes. This fraction increases when increasing heat flux but in all cases, the PDMS is never entirely burnt. Mica composite exhibits the lower fraction of consumed material for each heat flux (from 0.31 at $35 \mathrm{~kW} / \mathrm{m}^{2}$ to 0.61 at $75 \mathrm{~kW} / \mathrm{m}^{2}$ ), whereas the other aluminum-based composites

\footnotetext{
1 This calculation is highly dependent on the choice of the heat of combustion; for instance, using a lower value of $19.53 \mathrm{~kJ} / \mathrm{g}$ published elsewhere [Walters, R.N., Hackett, S.M., Lyon, R. E., Heats of combustion of high temperature polymers; Fire Mater, 2000; 24: 245-252] led to inconsistent results in our hands (the fraction of burnt PDMS was found higher than 1). These authors did not take into account in their estimation the formation of silica. Doing so, we found an EHC value of $22.7 \mathrm{~kJ} /$ $\mathrm{g}$ with the Huggett constant value of $13.1 \mathrm{~kJ} / \mathrm{g}$. Considering reasonably that the cone calorimeter is well-ventilated and that mineral fillers do not act as flame inhibitors, the choice of the heat of complete combustion given by Hshieh thus appears quite reasonable and was further used in our calculations.
} 

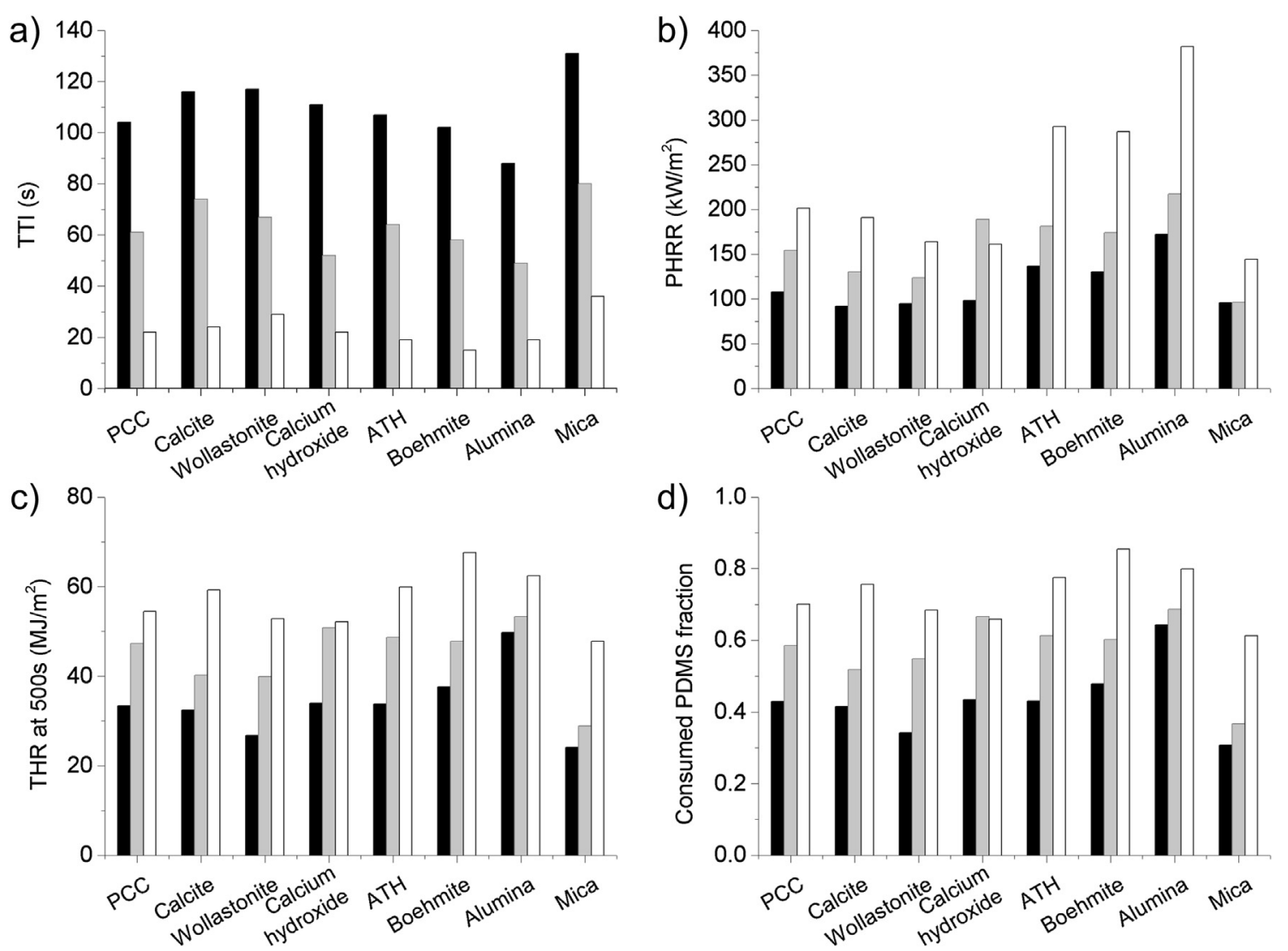

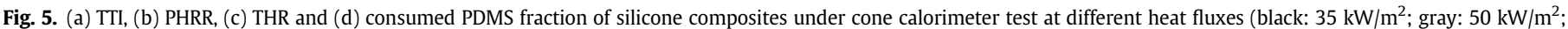
white: $75 \mathrm{~kW} / \mathrm{m}^{2}$ ).

(especially the one filled with alumina) exhibit the highest fraction (from $0.43-0.64$ at $35 \mathrm{~kW} / \mathrm{m}^{2}$ to $0.78-0.85$ at $75 \mathrm{~kW} / \mathrm{m}^{2}$ ). Calciumbased composites show an intermediate behavior.

We went further into the interpretation of weight losses, assuming the following equality:

Measured mass loss for silicone composites = calculated PDMS mass loss + estimated mass loss from filler decomposition - masst gain due to silica-ash deposition.

The filler weight loss as determined by TG analysis is given in Table $S 1,{ }^{2}$ whereas the two first parameters can be found in Fig. 6 and Fig. S5, and Fig. 5d, respectively. The mass losses from polymer degradation and from filler decomposition and the mass gain by deposition of silica ash are summarized in Fig. 7. The main observation is that ash deposition appears to increase slightly when increasing the heat flux, at least for calcium-based composites. Moreover, the amount of deposited silica ash seems to be higher for calcium-based composites than for aluminum-based composites (at $50 \mathrm{~kW} / \mathrm{m}^{2}$, the amount of deposited silica-ash is 3.2-5.8 $\mathrm{g}$ for calcium-based composites versus $0-2.9 \mathrm{~g}$ for aluminum-based composites). Note that there is no simple correlation between the amount of silica-ash deposited and the pHRR. For example, at

\footnotetext{
2 Note that for PCC and calcite, the mass loss was considered equal to $0 \%$ because the temperature of their decomposition, as measured by TG, is not reached in the cone calorimeter test.
}

$50 \mathrm{~kW} / \mathrm{m}^{2}$, the mica composite exhibits the lowest pHRR but also one of the lowest amount of deposited silica ash.

\subsubsection{Residues structures}

The microstructures of the surface and the interior of residues after the cone calorimeter test were observed by SEM under $5000 \times$ and $20,000 \times$ magnification. In this article, only SEM images of surface and interior residues of selected composites will be presented in Figs. 8 and 9, whereas the other composites' residues can be found in supporting information (Figs. S7 and S8). After pyrolysis to $940{ }^{\circ} \mathrm{C}$ [24], we observed that each composite exhibited a continuous surface layer with mica and wollastonite-based

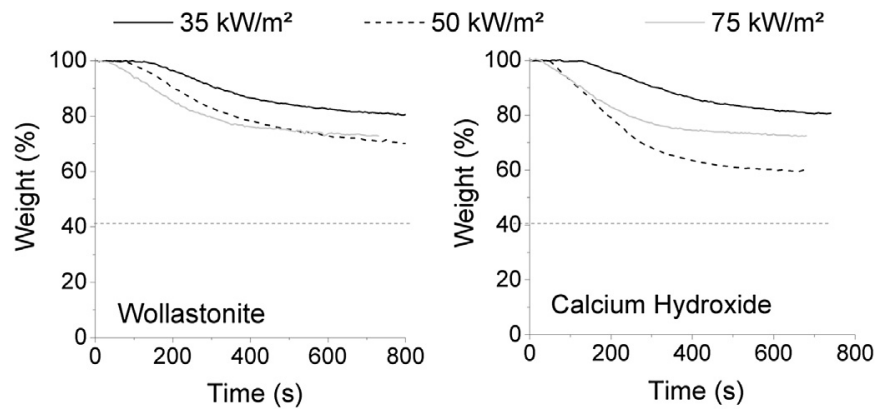

Fig. 6. Weight versus time during cone calorimeter tests for wollastonite and calcium hydroxide composites irradiated at 35 (dark line), 50 (dashed line) and 75 (gray line) $\mathrm{kW} / \mathrm{m}^{2}$. The curves for the other composites are given in Fig. S5. 

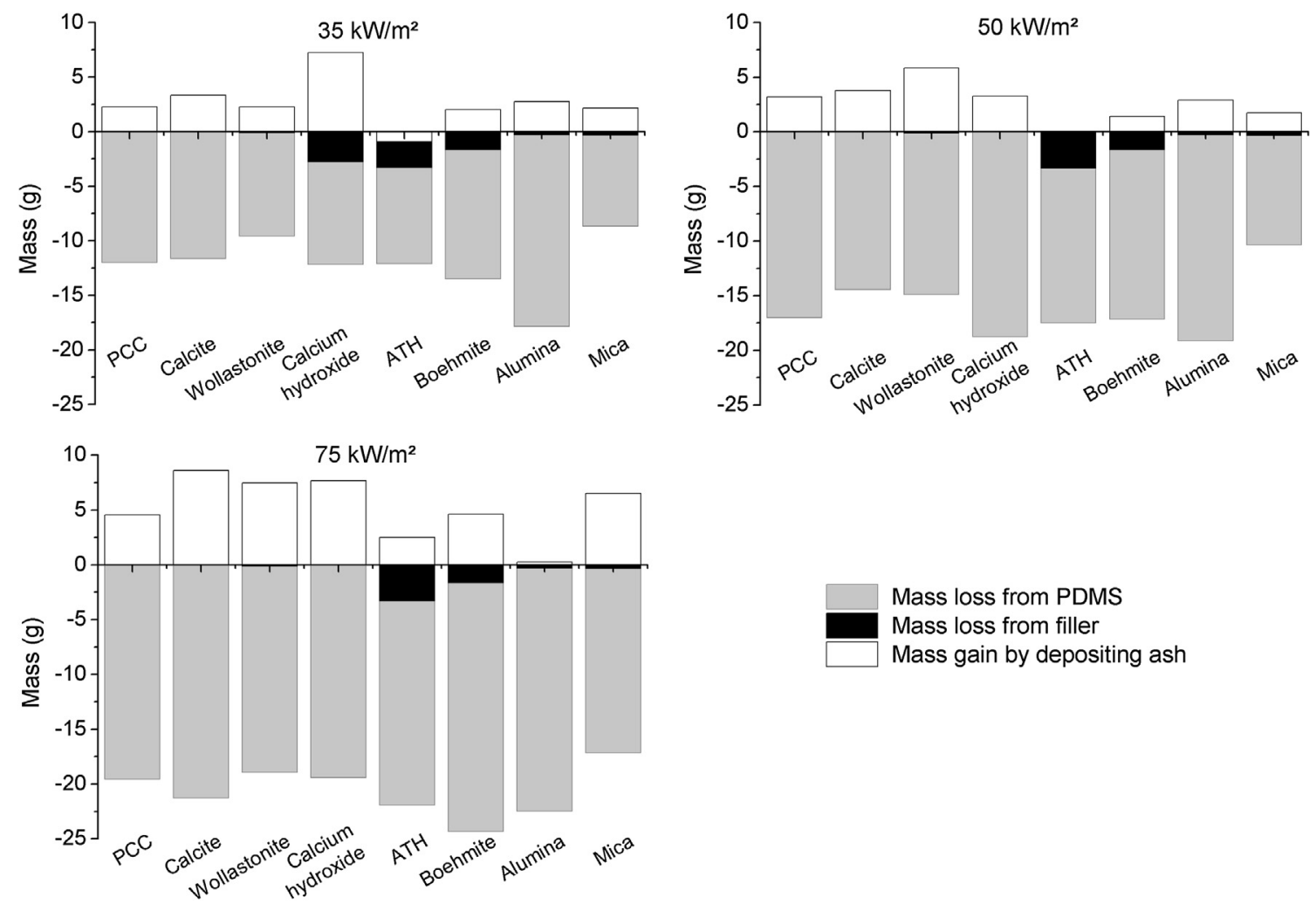

Mass loss from PDMS

Mass loss from filler

Mass gain by depositing ash

Fig. 7. Mass losses from PDMS and from filler and mass gain by depositing ash for silicone composites at 35,50 and $75 \mathrm{~kW} / \mathrm{m}^{2}$.

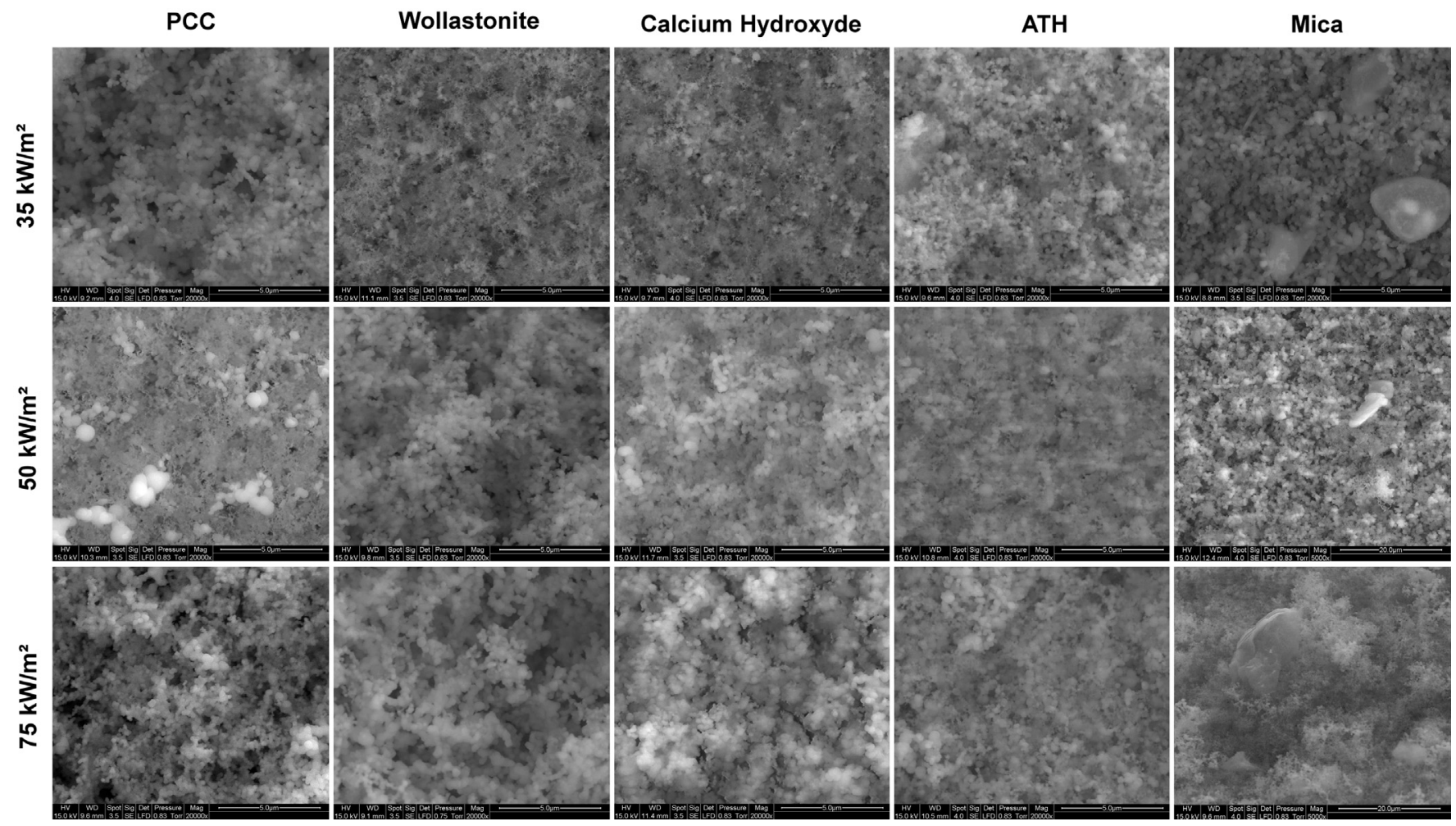

Fig. 8. SEM images $(20,000 \times)$ on the surface of some residues after cone calorimeter test (except residue of mica is under magnification of $5000 \times$ ). The images for missing composite residues are given in Fig. S7. 


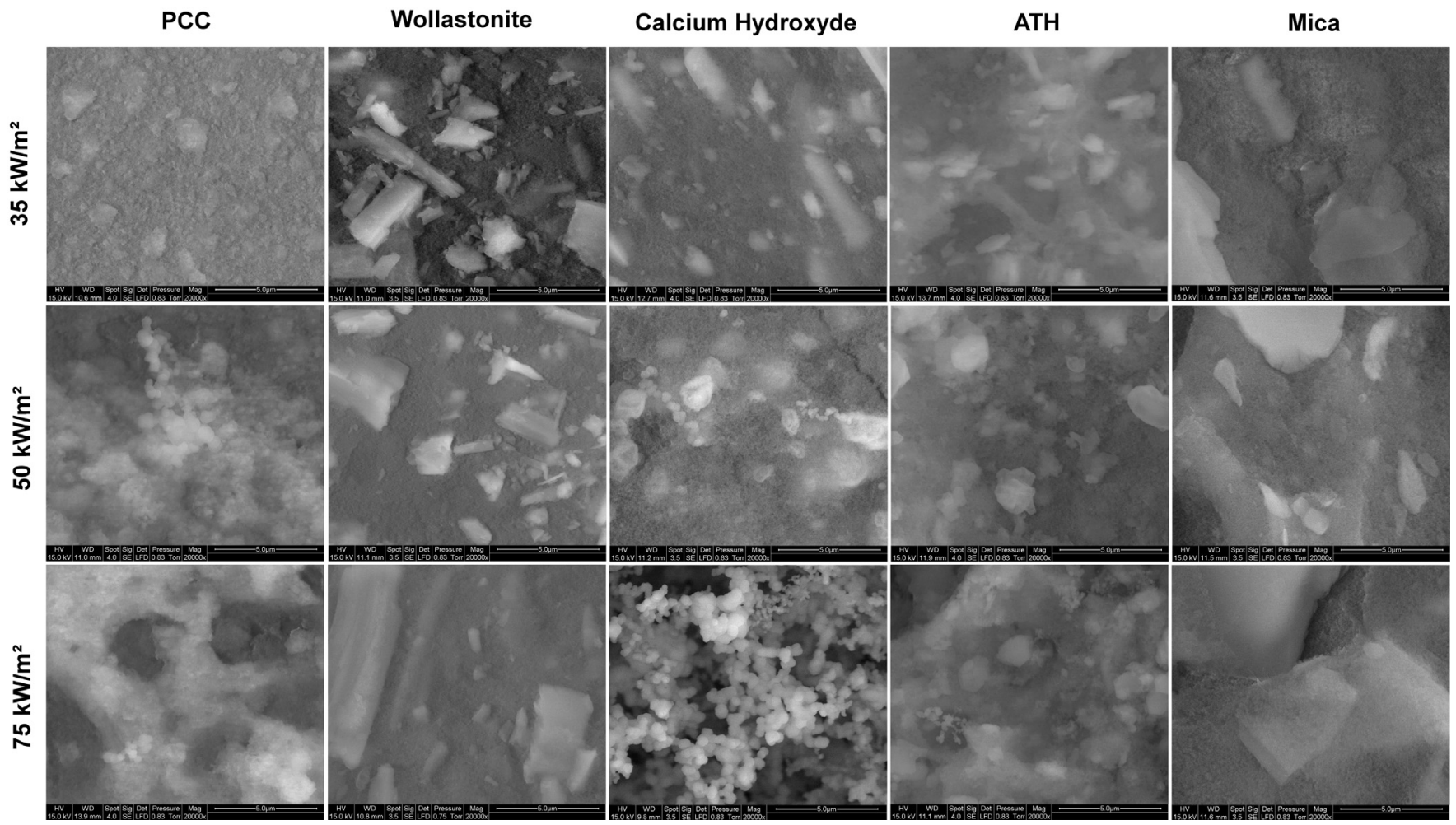

Fig. 9. SEM images $(20,000 \times)$ on the interior of residues after cone calorimeter test. The images for missing composite residues are given in Fig. S8.

composites' residues presenting filler particles on the surface. Here, the surface residues of all silicone composites after cone calorimeter test present identical apparent microstructures at all heat fluxes. The presence of some porosities was clearly observed under $20,000 \times$ magnification, a consequence of volatile release during matrix or filler decomposition. Among all residues, only the micabased composite residue (at all heat fluxes) exhibited clearly the presence of filler particles on surface; this may be due to the migration of platelets of filler during combustion (Fig. 8).

The interior morphology of residues varies more significantly than those observed on their surfaces (Fig. 9). The presence of big filler particles was observed in the interior of residues, not nanosized ones, even at higher magnification $(20,000 \times)$; this absence may be ascribed either to the low resolution of SEM apparatus, and/ or to fillers volatilization during combustion [26]. On the whole, all composites interior microstructure evolved with heat fluxes, except for alumina composites which systematically led to a smooth fragile residue. Boehmite and PCC composites presented smooth microstructures under the lowest heat flux, together with some big holes at higher heat flux, which were ascribed to a release of some volatiles, especially for PCC. The presence of calcite, ATH and calcium hydroxide particles were observed on residues at a heat flux of $35 \mathrm{~kW} / \mathrm{m}^{2}$, but these particles decreased in content when the heat flux increased. At all heat fluxes, the interior residue of ATH composite presented some big porosities which increased by increasing the heat flux, whereas calcite and calcium hydroxide composites only presented low porosities. Under a heat flux of $75 \mathrm{~kW} / \mathrm{m}^{2}$, the calcium hydroxide composite showed a glassy sintered residue's microstructure, which was not observed at $50 \mathrm{~kW} / \mathrm{m}^{2}$ (Fig. 9). That observation may indicate the formation of a new crystalline phase (wollastonite) as observed previously and confirmed here by XRD analysis (see below). Finally, big particles of wollastonite and mica particles were always found in the interior of the residues, indicating a high thermal stability of these fillers towards temperature even under heat flux of $75 \mathrm{~kW} / \mathrm{m}^{2}$ during cone calorimeter test.
The different residue's morphologies from cone calorimeter tests correlate quite well with the shape of HRR curves. For example, under a heat flux of $35 \mathrm{~kW} / \mathrm{m}^{2}$, the PCC composite presented HRR curve with plateau, while ATH composite presented several peaks. When the burning process was stopped at the time when the PHRR was attained, and then the sample morphology was observed, different microstructures were found. SEM images of PCC composite's residue showed less porosities than for one observed in ATH composite (Fig. S9), and microstructures identical to those seen at the end of the cone calorimeter test (Fig. 8).

\subsubsection{Crystallinity of residues}

XRD analyses were carried out on all residues of composites containing aluminum and calcium-based fillers after the cone calorimeter test. The formation of a new crystalline structure (quoted as co-crystallization in our previous paper [23]), could occur as the result of interaction between fillers and matrix residues at high temperature. Under heat fluxes of 35 and $50 \mathrm{~kW} / \mathrm{m}^{2}$, no cocrystallization occurred in residues; presumably, in these conditions, the temperature in the condensed phase was not high enough to generate new crystals. At $75 \mathrm{~kW} / \mathrm{m}^{2}$ however, calcium hydroxide composites generated wollastonite crystals $\left(\mathrm{CaSiO}_{3}\right)$ (Fig. 10a), and PCC a small amount of larnite $\left(\mathrm{Ca}_{2} \mathrm{SiO}_{4}\right)$ (Fig. 10b). Nano-sized calcium carbonate (PCC) degraded earlier than bigger particles of calcium carbonate (calcite), ensuring co-crystallization reaction only for PCC composite. The presence of calcite crystals in PCC residue signifies an incomplete burning of composite during the cone calorimeter test.

\subsection{Pyrolysis Combustion Flow Calorimeter and analysis of pyrolysis volatile products}

The PCFC test was performed here in order to complement the fire retardant mechanism of silicone composite working at the milligram scale. Using this technique, the barrier effect is neglected since thin films are burned. As a convention, the heat release 

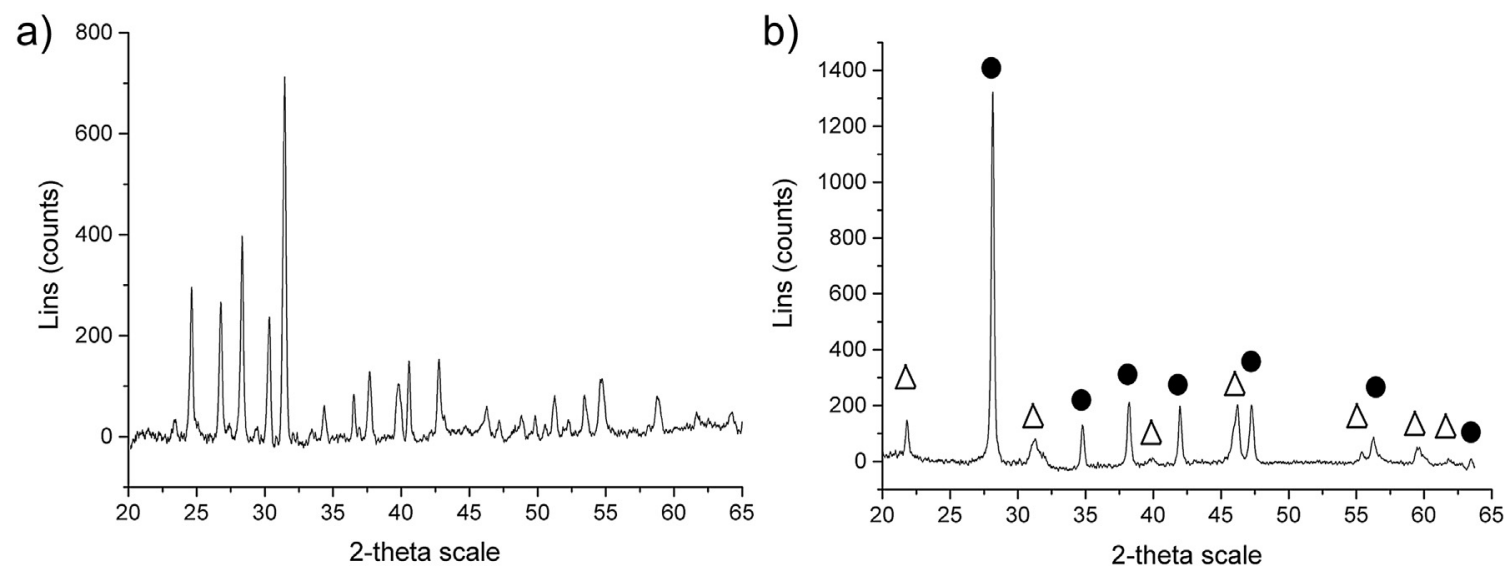

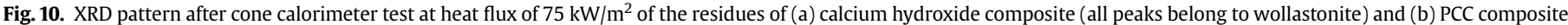
(- calcite, $\triangle$ larnite $\left(\mathrm{Ca}_{2} \mathrm{SiO}_{4}\right)$ ).

evolution during sample pyrolysis in PCFC test is presented simultaneously with the derivative of the mass loss rate observed during pyrolysis by TG, as taken from a previous work (replotted in Fig. S6) [23]. Py-GC/MS was also carried out on temperature of the maximum HRR value attained under PCFC test to identify the different types of released volatiles at this critical temperature.

\subsubsection{PCFC test results}

HRR curves in PCFC and mass loss rate curves in TG are globally well correlated (Figs. 11 and 12). Curves are slightly shifted to higher temperatures in PCFC due to a higher heating rate $\left(1^{\circ} \mathrm{C} / \mathrm{s}\right.$ for PCFC versus $10{ }^{\circ} \mathrm{C} / \mathrm{min}$ for TGA). Three discrepancies could be noticed between both techniques: ATH composite exhibits a first mass loss rate peak in TGA not seen in HRR curve, attributed to water release which starts from $200^{\circ} \mathrm{C}$; PCC and calcite composites exhibit an extra mass loss rate peak after $700{ }^{\circ} \mathrm{C}$ in TGA, assigned to a $\mathrm{CO}_{2}$ release from decomposition of $\mathrm{CaCO}_{3}$. In all other cases, correlation between mass loss rate and HRR shows that degradation steps correspond to combustible gases release (and sometimes additional water or $\mathrm{CO}_{2}$ release), arising from the degradation of PDMS matrix. The degradation is complex and does not occur in one step; indeed, most HRR curves are multimodal.

According to Table 1 [23,27], all composites exhibit roughly similar pHRR and HR. PDMS is fully decomposed in PCFC test because the maximal temperature is high enough $\left(780^{\circ} \mathrm{C}\right)$ so that the total heat released is the same from one composite to another. The mica composite exhibits a substantially lower pHRR than others (108 W/g against $120-140 \mathrm{~W} / \mathrm{g}$ ) whereas boehmite and wollastonite composites exhibit the highest ones. Nevertheless, it is difficult to compare these pHRR since the temperatures at which they occur are significantly different. Onset temperatures in HRR curves (arbitrarily measured as the temperature for which HRR

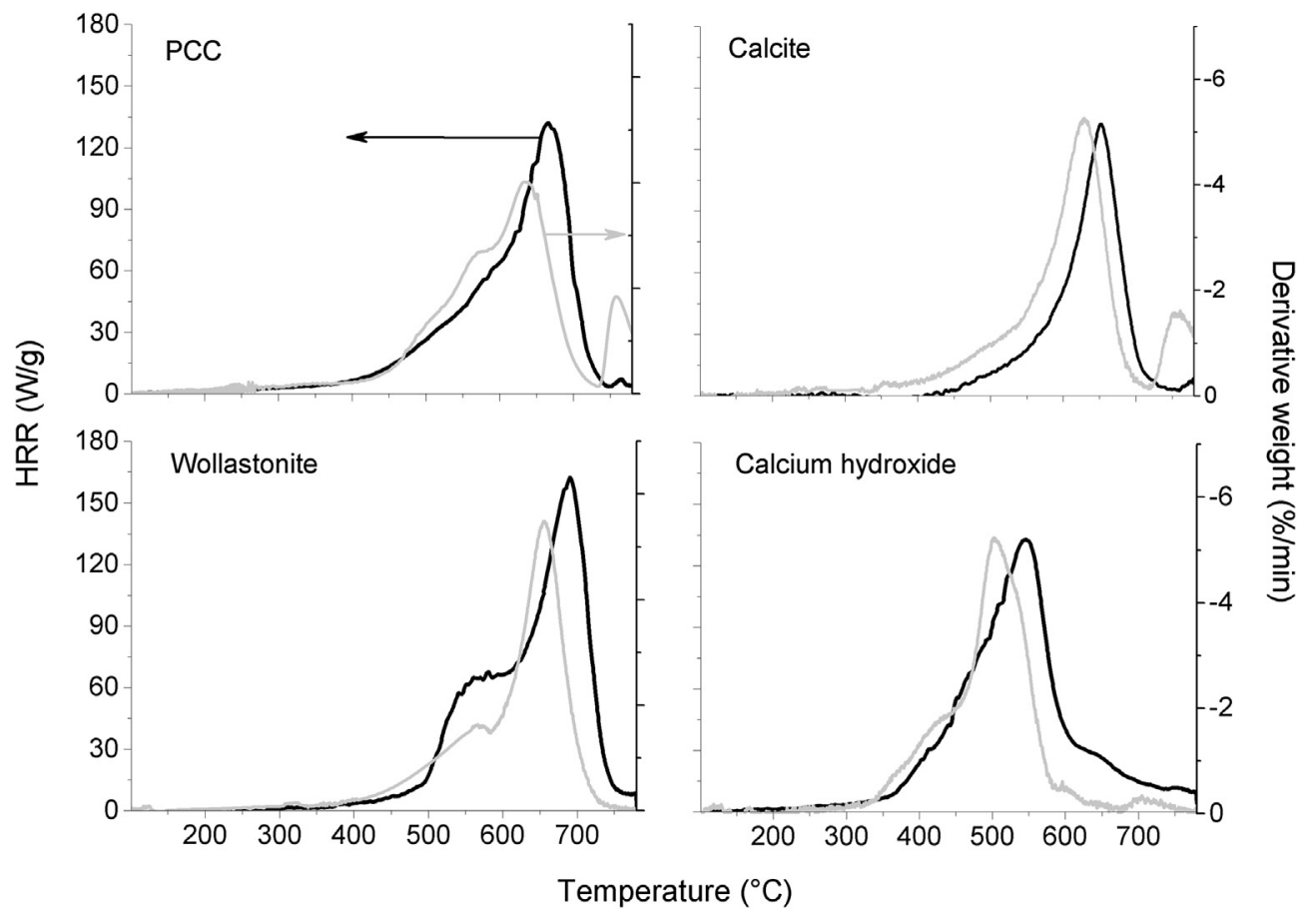

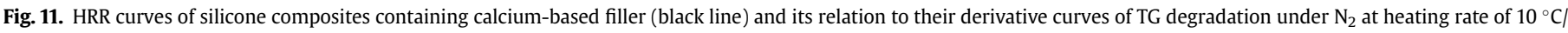
min (gray line). 


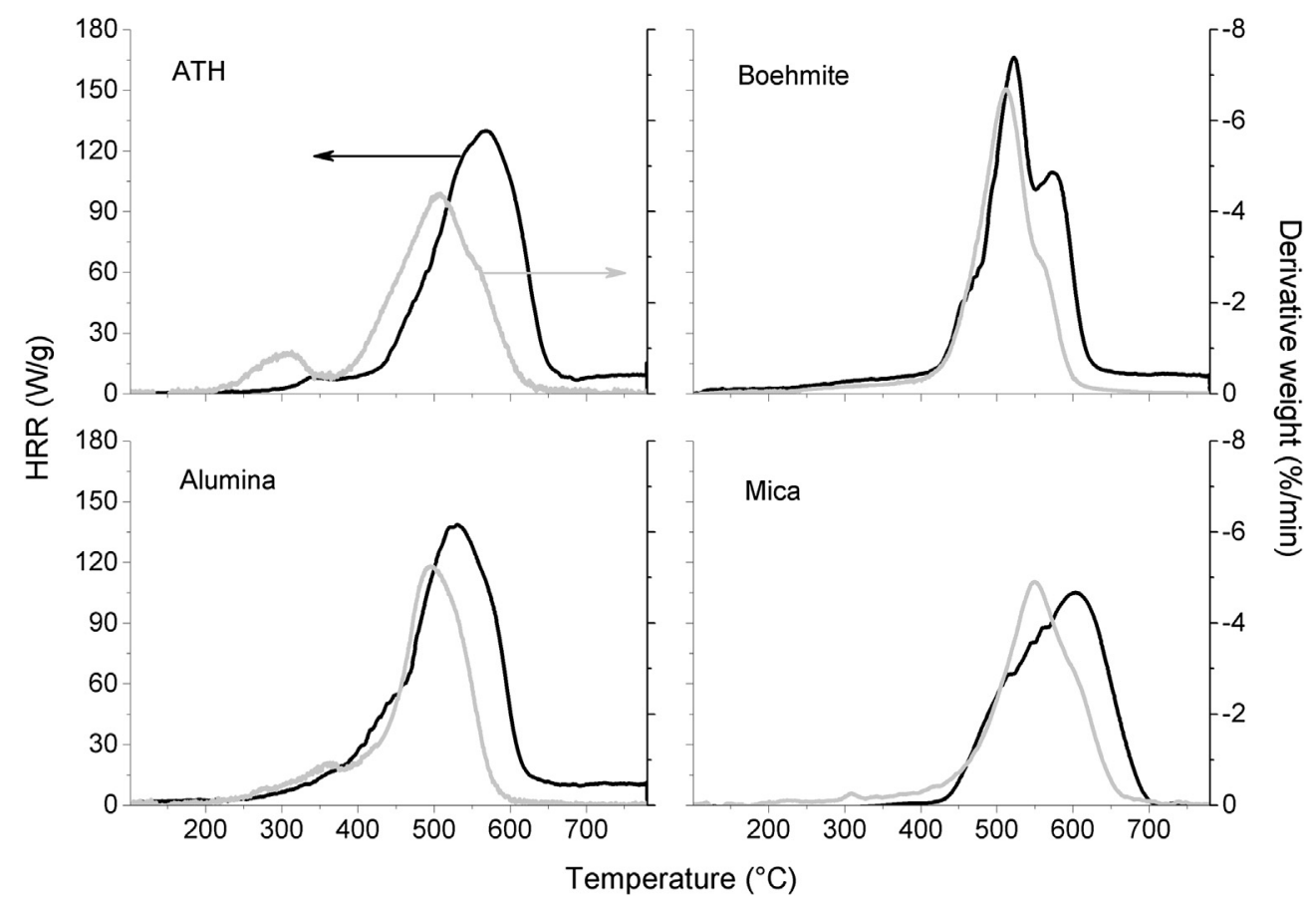

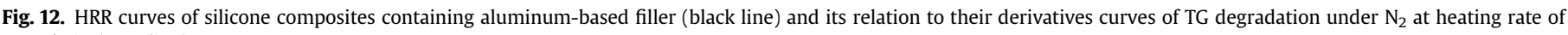
$10^{\circ} \mathrm{C} / \mathrm{min}$ (gray line).

attains $30 \mathrm{~W} / \mathrm{g}$ ) and temperature at pHRR are different according to the type of filler introduced (Table 1); calcium-based filler composites exhibit onset temperature and temperature at pHRR superior to $500{ }^{\circ} \mathrm{C}$ and $600{ }^{\circ} \mathrm{C}$ respectively, except for calcium hydroxide composite. On the contrary, aluminum-based filler composites have a lower thermal stability: onset temperature and temperature at pHRR are approximately $450{ }^{\circ} \mathrm{C}$ and lower than $600{ }^{\circ} \mathrm{C}$ respectively. The mica composite exhibits the highest temperature at pHRR for aluminum-based fillers $\left(600^{\circ} \mathrm{C}\right)$.

\subsubsection{Characterization of the volatiles from pyrolysis of composites}

In TG analysis, the weight loss observed was related to total volatile products, such as cyclic or linear siloxanes from matrix degradation and water and $\mathrm{CO}_{2}$ from filler decomposition. According to our previous TG study [23], the most abundant products in silicone composite degradation come from silicone (PDMS) degradation. From the literature, the decomposition products of vinyl-terminated PDMS at elevated temperatures are mainly cyclic oligomers hexamethyltrisiloxane (trimer; $D_{3}$ ) and octamethyltetrasiloxane

Table 1

HR, PHRR and TPHRR from PCFC test, total $D_{3} \& D_{4}$ from Py-GC/MS, and residues as obtained by TGA from different formulations of silicone composites.

\begin{tabular}{|c|c|c|c|c|c|c|}
\hline Filler & $\begin{array}{l}\text { PHRR } \\
(\mathrm{W} / \mathrm{g})\end{array}$ & $\begin{array}{l}T_{\mathrm{PHRR}} \\
\left({ }^{\circ} \mathrm{C}\right)\end{array}$ & $\begin{array}{l}\mathrm{HR} \\
(\mathrm{kJ} / \mathrm{g})\end{array}$ & $\begin{array}{l}\mathrm{D}_{3}+\mathrm{D}_{4} \\
\text { content (\%) }\end{array}$ & $\begin{array}{l}\text { Residues } \\
(\mathrm{wt} \%)^{\mathrm{a}}\end{array}$ & $\begin{array}{l}\Delta H_{\mathrm{f}} \text { of filler } \\
\text { decomposition } \\
(\mathrm{kJ} / \mathrm{g})^{\mathrm{b}}\end{array}$ \\
\hline PCC & 138 & 650 & 14.6 & 82 & 32.5 & 1.78 \\
\hline Calcite & 139 & 650 & 15.5 & 32 & 32.5 & 1.78 \\
\hline Wollastonite & 164 & 700 & 15.8 & 34 & 41.0 & 0 \\
\hline $\begin{array}{l}\text { Calcium } \\
\text { hydroxide }\end{array}$ & 127 & 550 & 13.6 & 53 & 41.0 & 1.15 \\
\hline ATH & 123 & 570 & 14.7 & 74 & 35.5 & 1.30 \\
\hline Boehmite & 158 & 525 & 17.8 & 46 & 39.0 & 0.61 \\
\hline Alumina & 131 & 525 & 16.7 & 64 & 38.0 & 0 \\
\hline Mica & 108 & 600 & 14.2 & 93 & 41.0 & 0 \\
\hline
\end{tabular}

a Obtained in TG analysis at $780^{\circ} \mathrm{C}$ [23].

b Obtained from Ref. [27]. (tetramer; $\mathrm{D}_{4}$ ), with small amounts of methane and traces of linear oligomers [28,29]. Moreover, under flash pyrolysis, it was shown that silicone degradation produces cyclic oligomers, with the tetramer being the most abundant, accompanied by other volatiles such as linear pentasiloxane or rearranged oligomeric siloxane compounds (e.g. tetrasiloxane, 3,5-diethoxy-1,1,1,7,7,7-hexamethyl-3,5-bis(trimethylsiloxy)) [30]. In our most recent study on silicone rubber fire degradation [12], we have also shown that $\mathrm{D}_{3}$ production arises mainly from silicone chains strongly interacting with the silica filler, whereas long oligomers arise from free moving chains. The formation of $\mathrm{D}_{4}$ is in between the two, basically it is produced from short PDMS loops (of less than $10 \mathrm{D}$ units) protruding from the silica interface.

Here, all silicone composites were subjected to successive flash pyrolysis for $5 \mathrm{~s}$ under helium at the temperature of pHRR (given from PCFC) of each formulation, which differs sensibly from one composite to another (see values reported in Table 1 and Fig. 13). $D_{3}$ and $\mathrm{D}_{4}$ volatiles were always present as pyrolysis products of silicone composites containing calcium and aluminum-based fillers, whereas the rest of the chromatogram differs from one formulation to another. The total compositions of $\mathrm{D}_{3}$ and $\mathrm{D}_{4}$ calculated from $\mathrm{GC} /$ MS chromatograms are given in Table 1 . We can distinguish three different behaviors according to the GC/MS traces: i) Mica and ATHbased composites produce exclusively small cycles, i.e. $\mathrm{D}_{3}$ and $\mathrm{D}_{4}$. Such effect is observed when most of the chains are physically covering the filler surface. We have shown before [23] that both fillers are covered by hydroxyl groups, favoring the adsorption and depolymerization of PDMS chains; ii) Alumina and PCC-filled elastomers generate a high load of cyclics of increasing size, up to typically 10 (or larger) D units. Both fillers exhibit a large specific surface (around 20 and $95 \mathrm{~m}^{2} / \mathrm{g}$ ) but a low affinity for silicone chains. It is anticipated here that all chains are weakly adsorbed on the filler, where they undergo depolymerization; iii) wollastonite, calcite and boehmite-based composites decompose into large molar mass linear chains, particularly at two very specific retention times (12 and 15 s, see Fig. 13). This typically happens for linear 

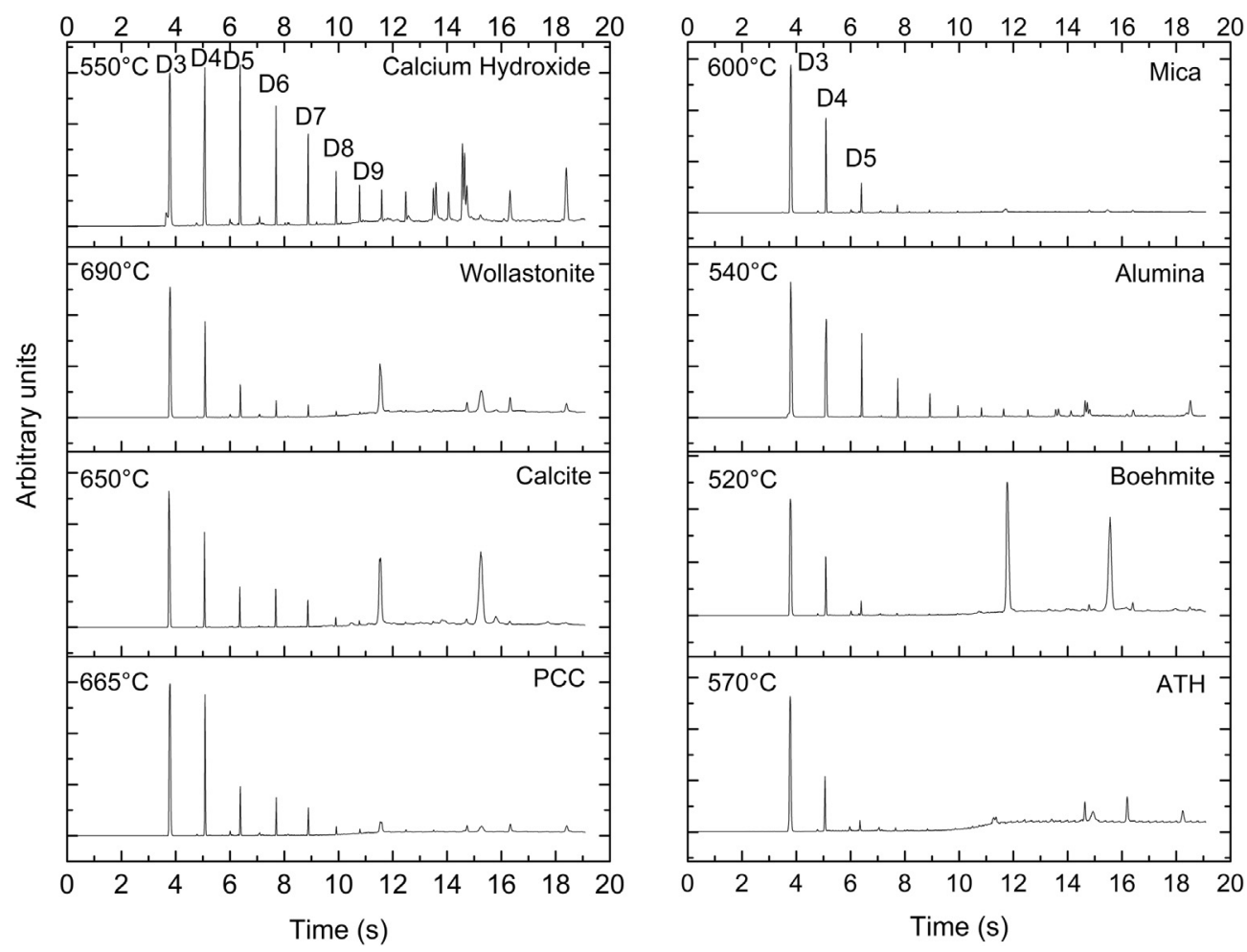

Fig. 13. GC-MS chromatograms of calcium and aluminum-based composites at the temperature of peak HRR (given on the top left of each chromatogram) during PCFC test.

PDMS chains being degraded in the bulk of the polymeric matrix. For these fillers, neither hydroxyl surface groups nor large specific surface area promote PDMS chain adsorption. Finally, calcium hydroxide-based composite produced very large contents of volatiles, both linear and cyclic oligomers; this unique filler has shown also a complex behavior in our late study on composite residues [24].

\section{Discussion}

The flame retardant mechanism of silicones has been reported in the literature to occur through the formation of a silica ash insulating layer limiting heat or mass transfer [9,13]. Mineral fillers may reinforce this layer to limit the heat and gases transfers. Nevertheless, other parameters such as an endothermic effect due to water release or the composite's own thermal stability could also be important. We have shown in the previous parts of this series
$[23,24]$ that the release of water or the generation of new crystalline structures after $\mathrm{CO}_{2}$ release could also largely affect the burning of silicone composite, albeit in inert conditions (TGA under nitrogen or pyrolysis in stainless steel tubes). The purpose of this discussion is to go further into the understanding of silicone combustion by comparing data obtained from two fire-testing techniques, i.e. Cone Calorimeter and PCFC. Also, we compared the state of residues by SEM and XRD and the volatile released to investigate specific fire behaviors. In the following, the discussion is illustrated exclusively with data taken at a heat flux of $50 \mathrm{~kW} / \mathrm{m}^{2}$. whereas curves for the other two irradiations are given in Supporting Information.

\subsection{Comparison of the two fire tests}

Fig. 14a shows the relation between TTI in cone calorimeter and onset temperature in PCFC. These two parameters basically show
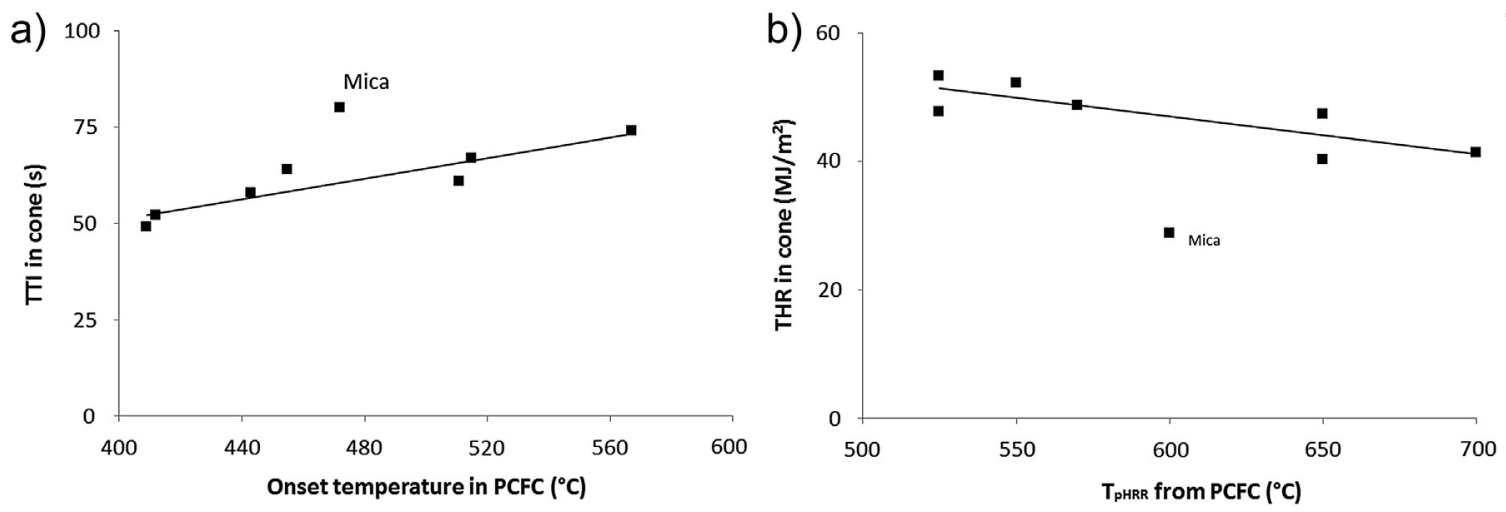

Fig. 14. a) TTI in cone calorimeter versus onset temperature in PCFC; b) THR in cone calorimeter versus temperature of PHRR in PCFC. 
the time needed to start the pyrolysis of the polymer (PCFC uses a temperature sweep with time). A linear correlation is observed between TTI and onset temperature, showing that the time of ignition/onset of degradation is only a matter of thermal stability of the composites, for this parameter anyway. One datum is not following the linear dependence, i.e. the mica-based composite (this is true also for the other irradiances, see Fig. S10). This latter has retarded ignition in the cone calorimeter compared to the observed onset temperature in PCFC. A barrier effect (discussed below) may explain this result. Fig. 14b shows the relation between THR in cone calorimeter and temperature at pHRR in PCFC ( $\left.T_{\mathrm{pHRR}}\right)$. This plot aims at comparing the effectiveness of composite degradation in cone calorimeter according to the thermal stability as observed by PCFC. Aluminum-filled composites give similar THR (except for Mica), whereas those for calcium-based fillers decrease according to the $T_{\mathrm{pHRR}}$ increase in PCFC. Such latter trend is typical of composites that partially burn, thanks to their enhanced thermal stability. We also observed that THR increases with the heat flux because a higher heat flux leads to a higher temperature in condensed phase and therefore to a higher fraction of degraded combustibles (see Fig. S11). The study of Patel indeed showed that the temperature of pyrolysis influences both the TTI and the HRR [31].

\subsection{Fire reactions}

Pyrolysis GC/MS measurements showed that a large quantity of combustible species is produced at pHRR as deduced from PCFC. Even if the nature of the molecules varies, the burning behavior is not believed to be different under the cone calorimeter conditions. Based on SEM images of surface and interior residues, wollastonite and particularly mica composites exhibit a more cohesive surface (less cracks) than others. This is correlated to a low pHRR followed by an HRR plateau. On the contrary ATH or boehmite composites exhibit more cracks and their HRR curves are characterized by several peaks; such cracks more likely occur from water release. A cohesive surface layer is able to limit efficiently the heat transfer from the flame to the condensed phase and the gas transfer from the condensed phase to the flame.

Hull et al. [32] have studied various hydrated mineral fillers as heat absorbers, excluding some other effects such as heat shielding, diffusion barrier, or catalytic effect. The heat absorption is believed to arise from the filler before decomposition, from the residue and the gas released (water) and from the endothermic decomposition of the filler. For all investigated fillers, the authors concluded that this last effect is the most effective (the endothermic decomposition contributes to more than $50 \%$ of the heat absorption). In our study however, no correlation was found between the endothermic enthalpy of filler decomposition (if any) and the heat release rate. This remark confirms that cooling the condensed phase through endothermic decomposition is not an effective mode-of-action for the flame retardancy of silicone in the cone calorimeter test. Probably, this effect is counter-balanced by the earlier decomposition of silicone through backbiting reactions [8].

In the specific case of the mica-based composite, the lamellarshaped mica particles (high aspect ratio) seen both inside and at the surface of the residue, probably act as an oxygen barrier (before ignition), a gas barrier and a heat shield (throughout the test), thus slowing down the burning rate. Another possible explanation for good performances is that mica could promote cross-linking or adsorb PDMS chains onto its surface resulting in restriction of segmental mobility. This lower mobility would suppress redistribution reactions during degradation and improve the residue yield [15]. A final explanation could come from the infrared reflectivity of the composites, especially when using (bright) mica particles.
A lower fraction of heat flux would be absorbed by the composites leading to a lower heating rate and a higher time to ignition. Hanu et al. [15] have indeed shown that mica could increase the thermal conductivity of PDMS, and thus retard polymer ignition.

When considering the calcium hydroxide-based composite, the fire latency may be related to the change of microstructure due to the ceramization occurring at high temperature (as proved by XRD analysis). A sintered residue's microstructure presumably insulates the condensed phase and lowers the degradation rate. The crystal formation in silicone flame retardant system containing chalk (natural calcium carbonate) has also been reported to improve its flame retardancy through the formation of a protective layer [3336]. Nevertheless, in our systems, PCC and calcite decompose at too high a temperature (i.e. above the degradation of PDMS) to favor a co-reaction with silica.

\section{Conclusion}

The fire reaction of silicone composites containing calcium and aluminum-based fillers has been investigated using cone calorimeter and PCFC tests. The residues after the cone calorimeter test and the gas production at the maximum HRR in PCFC test were also characterized. The combination of both calorimeter methods (cone calorimeter and PCFC) appeared to be a good strategy to better understand the fire reaction mechanism of their silicone composite. In the cone calorimeter test, the calcium-based fillers silicone composites presented a better fire behavior than the ones containing aluminum-based filler. In all formulations tested, increasing the heat flux resulted in a decrease in TTI and an increase in PHRR and THR. The mica composite exhibits a better fire behavior than other silicone composites that release gases, such as $\mathrm{CO}_{2}$ or $\mathrm{H}_{2} \mathrm{O}$; the endothermic effect is thus not an efficient explanation for flame retardancy mechanism. Rather, the respective fire reactions of PCC, calcite, calcium hydroxide, ATH, boehmite, and alumina composites were attributed mainly to their thermal stability (according to PCFC results), even if the shielding effect from the silica ash layer formed during the degradation could not be excluded (as proved by Hshieh [9]). The mica composite (and in some instance the calcium hydroxide one) showed an additional barrier effect and/or possibly a higher infrared reflectivity.

\section{Dedication}

François Ganachaud dedicates this article to all "squared bits from Brittany" (we miss you, Eric).

\section{Acknowledgments}

The authors would like to thank Belkacem Otazaghine for his precious help on Py-GC/MS analyses.

\section{Appendix A. Supplementary data}

Supplementary data related to this article can be found at http:// dx.doi.org/10.1016/j.polymdegradstab.2013.07.009.

\section{References}

[1] Nelson GL, Morgan AB, Wilkie CA. In: Wilkie CA, Morgan AB, Nelson GL, editors. Fire retardancy in 2009: fire and polymers V. Materials and concepts for fire retardancy. Washington: American Chemical Society; 2009. p. 1-7.

[2] Dvornic PR. Thermal stability of polysiloxanes. In: Jones RG, Ando W, Chojnowski J, editors. Silicone-containing polymers. Dordrecht, the Netherlands: Kluwer Academic Publisher; 2000. p. 185-212.

[3] George C, Pouchelon A, Thiria R. Hot-vulcanizable polyorganosiloxane compositions useful particularly for manufacturing electrical cables or wires, European Patent EP2007,/003,248; 2007. 
[4] Shephard KL. Flame resistant silicone rubber wire and cable coating composition, US Patent 6,239,378; 2001.

[5] Ota K, Hirai K. Flame-retardant silicon rubber composition for coating electrical wire and cable, US Patent 006,011,105; 2000, Dow Crowning Toray Silicone Co.

[6] Beauchamp M. Flame resistant electric cable. US Patent 5, 705, 774; 1998.

[7] Kunieda S, Ishino S, Nakai T, Hirai K, Matsushita T, Takeshita K. Process for insulating high voltage electrical conducting media US Patent 5,369,161; 1994.

[8] Hamdani S, Longuet C, Perrin D, Lopez-Cuesta JM, Ganachaud F. Flame retardancy of silicone-based materials. Polym Degrad Stab 2009;94:465-95.

[9] Hshieh FY. Shielding effects of silica-ash layer on the combustion of silicones and their possible applications on the fire retardancy of organic polymers. Fire Mater 1998;22:69-76.

[10] MacLaury MR. The influence of platinum, fillers and cure on the flammability of peroxide cured silicone rubber. J Fire Flam 1979;10:175-98.

[11] Hayashida K, Tsuge S, Ohtani H. Flame retardant mechanism of polydimethylsiloxane material containing platinum compound studied by analytical pyrolysis techniques and alkaline hydrolysis gas chromatography. Polymer 2003;44:5611-6.

[12] Delebecq E, Hamdani S, Raeke J, Lopez-Cuesta J-M, Ganachaud F. High residue contents indebted by platinum and silica synergistic action during the pyrolysis of silicone formulation. ACS Appl Mater Interfaces 2011;3:869-80.

[13] Buch RR. Rates of heat release and related fire parameters for silicones. Fire Saf J 1991;17:1-12.

[14] Genovese A, Shanks RA. Fire performance of poly(dimethyl siloxane) composites evaluated by cone calorimetry. Composites: Part A 2008;39:398-405.

[15] Hanu LG, Simon GP, Cheng Y-B. Thermal stability and flammability of silicone polymer composites. Polym Degrad Stab 2006;91:1373-9.

[16] Gardelle B, Duquesne S, Vandereecken P, Bourbigot S. Fire performance of curable silicone-based coatings, ACS book fire and polymers VI: new advances in flame retardant chemistry and science; 2012.

[17] Schartel B, Hull TR. Development of fire-retarded materials-interpretation of cone calorimeter data. Fire Mater 2007;31:327-54.

[18] Morgan AB, Bundy M. Cone calorimeter analysis of UL-94 V-rated plastics. Fire Mater 2007;31:257-83.

[19] Babrauskas V, Peacock RD. Heat release rate: the single most important variable in fire hazard. Fire Saf J 1992;18(3):255-72.

[20] Troitzsch HJ. In: Gachter R, Muller H, editors. Flame retardants: plastics additives. Cincinnati: Hanser Publisher; 1993. p. 709-48.

[21] Lyon RE, Walters RN. Pyrolysis combustion flow calorimetry. J Anal Appl Pyrolysis $2004 ; 71: 27-46$
[22] Sonnier R, Ferry L, Longuet C, Laoutid F, Friederich B, Laachachi A, et al Combining cone calorimeter and PCFC to determine the mode of action of flame-retardant additives. Polym Adv Technol 2011;22:1091-9.

[23] Hamdani S, Longuet C, Lopez-Cuesta JM, Ganachaud F. Calcium and aluminum-based fillers as flame-retardant additives in silicone matrices. I. Blends preparation and thermal properties. Polym Degrad Stab 2010;99: 1911-9.

[24] Hamdani-Devarennes S, Longuet C, Lopez-Cuesta JM, Ganachaud F. Calcium and aluminum-based fillers as flame-retardant additives in silicone matrices II. Analysis of composites residues from normed pyrolysis test. Polym Degrad Stab 2011;96:1562-72.

[25] Hshieh FY, Julien CJ. Experimental study on the radiative ignition of silicones. Fire Mater 1998;22:179-85.

[26] Motzkus C, Chivas-Joly C, Guillaume E, Ducourtieux S, Saragoza L, Lesenechal D, et al. Aerosols emitted by the combustion of polymers containing nanoparticles. J Nanopart Res 2012;14:687.

[27] Patnaik P, editor. Handbook of inorganic chemicals. New York: McGraw Hill; 2002.

[28] Radhakrishnan TS. New method for evaluation of kinetic parameters and mechanism of degradation from pyrolysis-GC studies: thermal degradation of polydimethylsiloxanes. J Appl Polym Sci 1999;73:441-50.

[29] Deshpande G, Rezac ME. The effect of phenyl content on the degradation of poly(dimethyl diphenyl) siloxane copolymers. Polym Degrad Stab 2001;74: 363-70.

[30] Camino G, Lomakin S, Lageard M. Thermal polydimethylsiloxane degradation. Part 2. The degradation mechanisms. Polymer 2002;43:2011-5.

[31] Patel P, Hull TR, Stec AA, Lyon RE. Influence of physical properties on polymer flammability in the cone calorimeter. Pol Adv Technol 2011;22:1100-7.

[32] Hull TR, Witkowski A, Hollingberry L. Fire retardant action of mineral fillers. Polym Degrad Stab 2011;96:1462-9.

[33] Hermansson A, Hjertberg T, Sultan BA. The flame retardant mechanism of polyolefins modified with chalk and silicone elastomer. Fire Mater 2003;27:51-70.

[34] Krämer RH, Blomqvist P, Hees PV, Gedde UW. On the intumescence of ethylene-acrylate copolymers blended with chalk and silicone. Polym Degrad Stab 2007;92:1899-910.

[35] Hermansson A, Hjertberg T, Sultan BA. Linking the flame-retardant mechanisms of an ethylene-acrylate copolymer, chalk and silicone elastomer system with its intumescent behaviour. Fire Mater 2005;29:407-23.

[36] Hermansson A, Hjertberg T, Sultan BA. Distribution of calcium carbonate and silicone elastomer in a flame retardant system based on ethylene-acrylate copolymer, chalk and silicone elastomer and its effect on flame retardant properties. J Appl Polym Sci 2006;100:2085-95. 